\title{
Case report of Double Valve Replacement with Coronary Artery Bypass Grafting with Supracoronary Ascending Aortic Replacement in a Single Patient - A Chimera
}

\author{
Saikat Das Gupta ${ }^{1}$, Jagadananda Roy ${ }^{2}$, Mujibul Hoque ${ }^{2}$, Bhabesh C Mandol' ${ }^{2}$ P K Chanda ${ }^{1}$ \\ ${ }^{1}$ Department of Cardiac Surgery, Square Hospitals Limited, Dhaka, ${ }^{2}$ Department of Cardiac \\ Anesthesia, Square Hospitals Limited, Dhaka
} Aortic valve, Mitral valve, $C A B G$, Aortic aneurysm.

\begin{abstract}
Keywords: $\quad$ Double valve replacement is now-a-days a common procedure to treat diseased cardiac valves Prosthetic valve, and the primary aim of prophylactic aortic replacement during concomitant valve replacement

Abstract:

is to prevent dreadful complication like dissection, aortic rupture and even death. Although aortic surgeries are complex and have high morbidity and mortality rates, additional double valve procedure with coronary surgery can make it even worse. But for these patients, surgery remains the one and only treatment option for symptom relieve and prolongation of life. We herein present a case of severe aortic stenosis (AS) with severe aortic regurgitation (AR) with severe mitral regurgitation (MR) with coronary artery disease (CAD) and aortic aneurysm treated successfully by us at Square Hospitals; and to our best knowledge and according to the published articles, this is probably the first time, this type of combined cardiac procedure has been accomplished along with aortic surgery, in our country. We recommend that surgeons should perform bypass grafting along with aortic replacement and valve replacement surgery when indicated, without worrying that adding such a procedure will escalate post-operative adverse effect.
\end{abstract}

(Cardiovasc j 2021; 14(1): 82-87)

\section{Introduction:}

Concomitant coronary and valve diseases is rising with the increasing age of patients, referred for cardiac operations. If aortic stenosis (AS) is severe or the patient is symptomatic, single-stage aortic valve replacement and coronary artery bypass grafting (CABG) should be carried out. ${ }^{1}$ Most authors approve that performing $\mathrm{CABG}$ with aortic valve replacement (AVR) marginally increases long-term survival, even in the high-risk population. ${ }^{2}$ Calcified $\mathrm{AS}$ is frequently associated with coronary artery diseases and coronary grafting is mandatory during the AVR procedure in those patients. ${ }^{3}$

Severe aortic valve disease is now and then associated with dilation of the ascending aorta.
Hemodynamic flow disturbance in the aorta beyond the stenotic valve is one possible cause of dilatation, the second possibility is genetic predisposition to aortic dilatation. Ascending aortic dilatation usually give rise to aneurysm, dissection and rupture, and insufficiency of aortic valve. ${ }^{4}$ The aorta is defined aneurysmatic when there is a $50 \%$ increase in its normal diameter. ${ }^{5}$

Simply performing AVR in an aneurysmal aorta with aortic valvular disease cannot reduce the risk of fatal aortic complications. In patients with bicuspid aortic valve after AVR only, the aorta continues to enlarge and aorta-related complications increase. ${ }^{6,7}$ This is because of intrinsic changes in the aortic wall not because of

Address of Correspondence: Dr. Saikat Das Gupta, Department of Cardiac Surgery, Square Hospitals Limited, Dhaka, Bangladesh. saikatdasgupta@ymail.com

- 2020 authors; licensed and published by International Society of Cardiovascular Ultrasound, Bangladesh Chapter and Bangladesh Society of Geriatric Cardiology. This is an Open Access article distributed under the terms of the CC BY NC 4.0 (https://creativecommons.org/licenses/by-nc/4.0) 
the primary surgery. The time interval between initial AVR and late ascending aortic events ranged from 2 to 18 years. $^{8}$ The current ACC/ AHA guidelines recommend concomitant replacement of a significantly enlarged ascending aorta at the time of cardiac surgery. ${ }^{9}$ We herein present a case of severe AS with severe AR with severe MR with CAD with aortic aneurysm treated successfully by us at Square Hospitals.

\section{Case Report:}

Mr. X, 69 years of age, hypertensive, non-diabetic gentlemen got admitted to our hospital with the diagnosis of severe AS with severe AR with severe MR with pulmonary hypertension. Patient had complaints of central compressive chest pain on mild exertion for the last $1 \frac{1}{2}$ years, which was associated with profuse sweating \& breathlessness. Patient had no history of fever, cough or radiating pain but had history of syncope \& pre-syncope several times during last $1 \frac{1}{2}$ years. He had a history of myocardial infarction (MI) one month back, for which he was admitted at local hospital and got 14 doses of low molecular weight heparin.

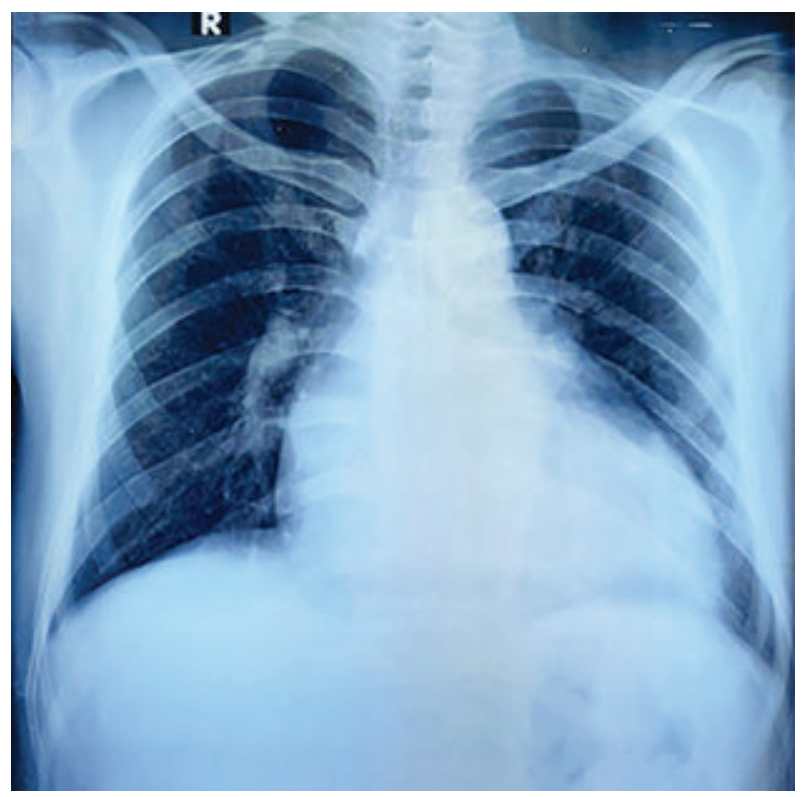

Fig 1: Pre-operative Chest $X$-ray PA view showing cardiomegaly.

Patient had no history of cerebrovascular accident (CVA), chronic kidney disease (CKD), chronic obstructive pulmonary disease (COPD) or Bronchial Asthma. All his biochemical investigations were within normal limits except

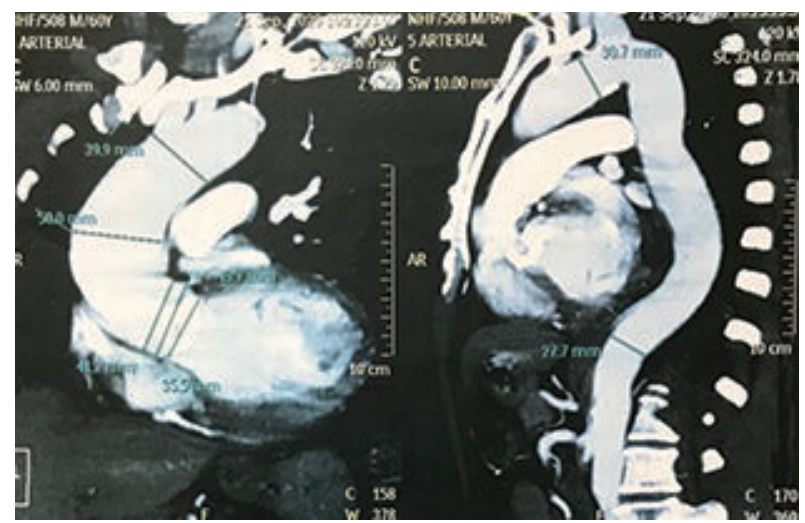

Fig 2: CT angiogram showing dilatation of ascending Aorta.

his NT pro BNP was $1107 \mathrm{pg} / \mathrm{ml}$. His body surface area (BSA) was $1.81 \mathrm{~m}^{2}$ and his serum creatinine was $1.0 \mathrm{mg} / \mathrm{dl}$.

Patients ECG showed left ventricular hypertrophy $(\mathrm{LVH})$ with Left axis deviation. Pre-operative echocardiogram showed bicuspid aortic valve, severe calcific AS (60/32 $\mathrm{mm}$ of $\mathrm{Hg})$ with severe AR. His aortic annulus was $20-21 \mathrm{~mm}$ with post stenotic dilatation of aortic root. Aortic sinus was $39 \mathrm{~mm}$, sinotubular junction (STJ) $28 \mathrm{~mm}$, and ascending aorta was $50 \mathrm{~mm}$. Redundant anterior mitral leaflet (AML) with tip prolapse causing severe eccentric MR. Mid distal IVS, mid anteroseptum, anterior and apex were hypokinetic with mild to moderate left ventricular (LV) systolic dysfunction (LVEF-40-45\%). Left atrium (LA), LV were dilated with concentric LVH and PASP 35 $\mathrm{mm}$ of $\mathrm{Hg}$. No pericardial effusion or intra-cardiac thrombus seen.

CAG on August 2020 showed left main coronary artery (LMCA): Free of disease; left anterior descending (LAD): Type IV vessel, 90\% stenosis in proximal segment. Left circumflex (LCX): 40\% stenosis in its proximal segment. Right coronary artery (RCA): Dominant vessel \& free of disease. His EUROScore II for in hospital mortality was $8.65 \%$.

\section{Surgery:}

Consequently, optimization of the patients' physical condition was done and on a fine morning of October 2020, patient was brought to OR for surgical correction. Central venous line (Right, jugular), left radial and femoral arterial lines, rectal and nasal temperature probes along with NIRS 
(near infrared spectroscopy) were established. Under all aseptic precaution, under GA after proper positioning patient was operated through median sternotomy. TEE (Trans-esophageal echocardiogram) was done to confirm myocardial, valvular and aortic pathology. Pericardiotomy was done and LIMA harvested. As soon as heparinization done and ACT achieved, we went to $\mathrm{CPB}$ with aortic and bi-caval cannulation. Heart arrested at diastole with cold blood cardioplegia after applying X clamp and patient was cooled to $28^{\circ} \mathrm{c}$. Aorta was then transected; aortic valve inspected, found severely calcified and valve excised. Mitral valve approached through superior septal atriotomy and valve was checked. Mitral valve cusps were found thickened, grossly distorted; saline test showed severely regurgitant mitral valve, and valve cusps were hardly repairable. So, without making any repair attempt mitral valve was excised and replaced with $27 \mathrm{~mm}$ PERIMOUNT tissue valve and atriotomy was closed. Subsequently AVR was done with $25 \mathrm{~mm}$ HANCOCK tissue valve. Aneurysmal ascending aorta was then replaced with $26 \mathrm{~mm}$ DACRON tube graft.

Aortic X clamp was released after de-airing and warming started. LIMA to LAD anastomosed with 8-0 proline. Heart weaned from CPB to normal sinus rhythm. TEE showed normally functioning prosthetic heart valves. Protamine was given and de-cannulation was done. Total CPB time was 221 minutes and aortic X clamp time was 161 minutes. Chest was closed in layers after proper hemostasis and keeping $\mathrm{RV}$ pacing wire and chest drain tubes
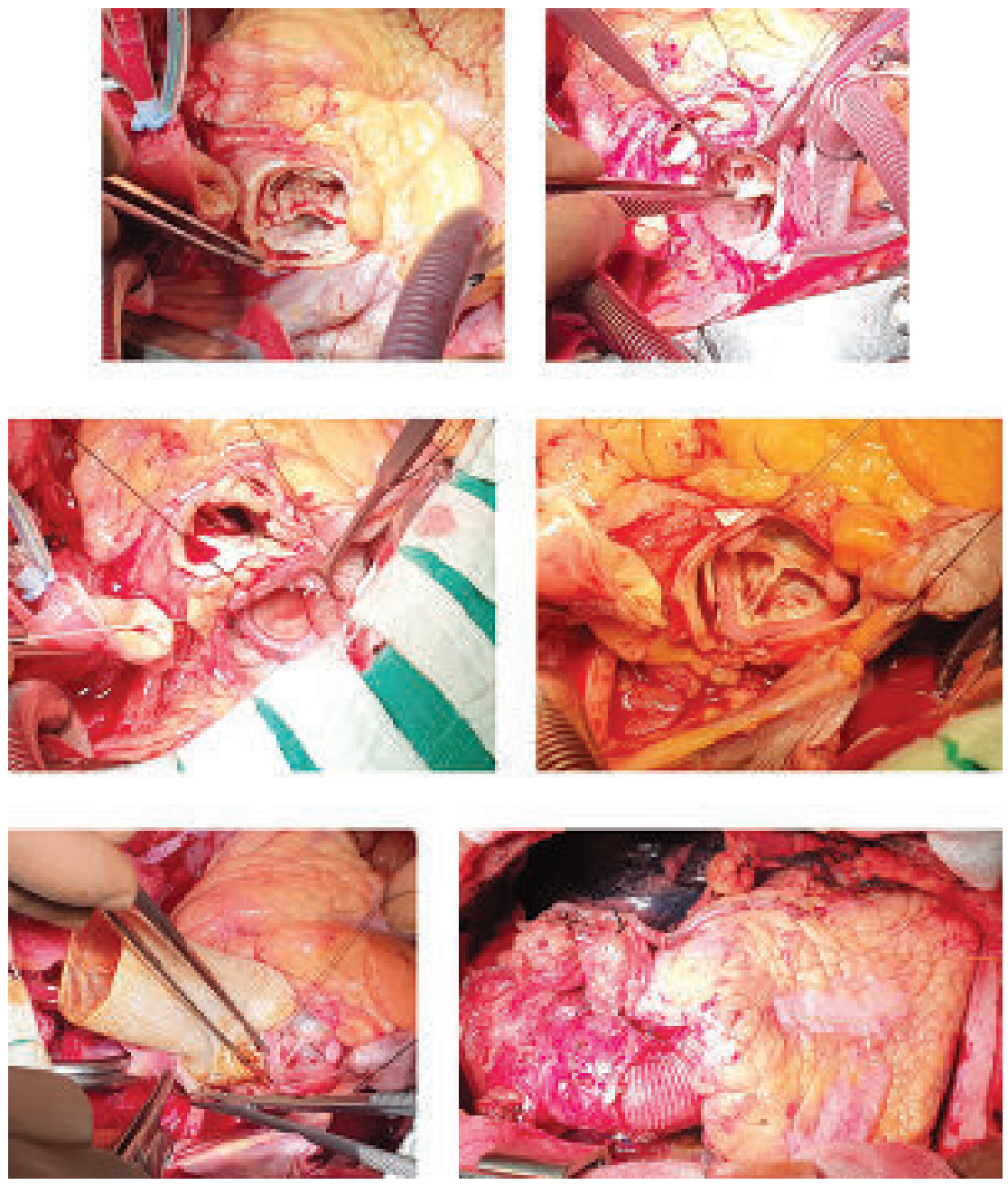

Fig 3: a) Calcified Aortic valve just after Aortic transection, b) Redundant AML held by forceps, c) Tissue Valve seen at mitral position, d) Tissue valve seen at aortic position through transected Aorta, e) Aortic reconstruction with tube graft, f) Heart with replaced aorta and LIMA-LAD graft just before chest closure 
in situ. Patient was shifted to ICU with minimum inotropic support. He was extubated on the subsequent day without any hassle.

Post-operative echocardiogram showed well seated $\&$ functioning Mitral and Aortic bio-prosthesis with trivial central AR \& MR. No paravalvular leakage seen. Normal laminar flow inside aortic tube graft. No gross regional wall motion abnormality seen. Dilated LA and concentric LVH seen. Fair LV systolic function (EF-55\%) and PASP was 35-40 mm of $\mathrm{Hg}$. No pericardial effusion or intra-cardiac thrombus seen. Patient's in hospital course was eventless and he was discharged on 7th POD without any residual complications. He was discharged with Warfarin, dual- Antiplatelets, Statin and Diuretics with an INR of 1.98. Follow up of the patient after 6 months showing gross improvements (freedom from exertional chest discomfort and breathlessness) during routine daily work.

\section{Discussion:}

Recently, as the patient population undergoing cardiac surgery has grown older, the need for concomitant procedures has become more common, with good number patients having CAD. It is estimated that $15-20 \%$ of patients who have ascending aortic aneurysms have CAD. ${ }^{10} \mathrm{In}$ patients with aortic aneurysm, CAD is typically seen in older, male patients, with tricuspid aortic valves (vs bicuspid valves, where CAD is relatively less). ${ }^{11,12}$ Although in our case patient was having bi-cuspid aortic valve.

$\mathrm{CAD}$ is also a common finding in patients undergoing endovascular or surgical repair of descending, thoraco-abdominal or abdominal aortic aneurysms. ${ }^{13,14}$ In patients undergoing planned aortic reconstruction, if pre-operative coronary angiogram shows significant stenosis, complete revascularization must be performed ${ }^{15}$, to reduce the adverse postoperative cardiac events. The only predictor of peri-operative myocardial infarction (PMI) in patients with known CAD was incomplete revascularization, highlighting the importance preoperative diagnosis as well as treatment of coronary stenosis. ${ }^{16}$ Therefore, concomitant CABG has begun to be performed more frequently, with an incidence of $11-25 \%$ in some larger aortic surgery studies. ${ }^{17-19}$
The natural prognosis of aortic aneurysm is associated with aortic diameter, mechanical properties of the vascular wall, and blood pressure. Aortic diameter has been best studied and is considered the primary prognostic parameter. ${ }^{20}$ Type I aortic dissection occurs in $0.6 \%$ of patients, late after $\mathrm{AVR}^{21}$ and $13 \%$ of patients with acute type I aortic dissections had a history of previous AVR. ${ }^{22}$ However, the incidence of dissection and rupture increases with increasing size of the ascending aortic aneurysm. ${ }^{23}$

Aneurysmal aorta can be treated in many ways; some surgeons ${ }^{24}$ suggest a conservative approach and remodel, others will replace using a tube graft, or with a valved conduit. When the aortic valve leaflets, the annulus and the sinuses of Valsalva are intact, the aneurysm is replaced with a simple supracoronary Dacron tube graft. But if the aortic valve is diseased but the aortic sinuses and annulus are normal, then AVR and a separate ascending aortic replacement (AAR) are performed. In cases with root dilation, a modified Bentall procedure is the gold standard.

Ascending aortic replacement is routinely performed today with excellent outcomes in high volume centers. ${ }^{25}$ Concomitant AAR during AVR does not increase the rate of morbidity and mortality in the short-term, despite the increase in aortic cross-clamp and total cardiopulmonary bypass times. ${ }^{26}$ According to the Society of Thoracic Surgeons (STS) database, the current in-hospital or 30-day operative mortality associated with replacement of the ascending aorta is $2.2 \%{ }^{27}$

The risks of aortic surgery include paraplegia, stroke, bleeding and death; however, rupture, dissection and death may also occur when the aneurysm is not corrected surgically. If no intervention is done at the time of cardiac surgery, the aneurysm may rupture, and will need a redo procedure, with additional technical challenges and complications. An initial concomitant surgery may increase the operative risks but protects patients from long-term complications.

The goal should be to avoid the catastrophic consequences of acute aortic dissection or rupture. ${ }^{20}$ Many studies support that, concomitant replacement of the ascending aorta should be performed at the time of other cardiac surgery to 
prevent possible aortic rupture, dissection or death. In our case we replaced the aorta along with $\mathrm{CABG}$ and double valve replacement and at 6 month follow up, patient was maintaining routine physical activity without any complication.

\section{Conclusion:}

Aortic surgeries are complex and have high morbidity and mortality rates, additional double valve procedure with coronary surgery make it even worse. For these patients, surgery remains the one and only comprehensive treatment for symptom relieve and extension of life. But with proper planning, maximum myocardial protection, minimum cross clamp and CPB time, meticulous technique, off course with dedicated and capable aortic team, AAR can be performed with concomitant CABG and DVR with acceptable outcomes. Many more dedicated aortic programs should be initiated to maneuver on these complex cardiac patients with logical risks and reasonable outcome.

\section{Acknowledgements:}

The authors would like to acknowledge Dr. Mesbah Uddin Dolon, Mr. Mohammad Kamal Uddin, Mr. Tanvir Ahmed for their relentless effort during surgery and Dr. Sheikh Nafis Ur Rahman, Md. Rana Masud for their tenacious radiological support.

\section{Conflict of Interest - None.}

\section{References:}

1. Lima B, Hughes GC, Lemaire A, Jaggers J, Glower DD, Wolfe WG. Short-term and intermediate-term outcomes of aortic root replacement with St. Jude mechanical conduits and aortic allografts. Ann Thorac Surg. 2006; 82: 579-585. DOI: org/10.1016/ j.athoracsur.2006.03.068

2. Roman M, Devereux R, Kramer-Fox R, O’Loughlin J. Two-dimensional echocardiographic aortic root dimensions in normal children and adults. Am J Cardiol. 1989; 64(8): 507-512. DOI: 10.1016/0002-9149(89) 90430-x.

3. Hiratzka L, Bakris G, Beckman J et al. 2010 ACCF/ AHA/AATS/ACR/ASA/SCA/SCAI/SIR/STS/SVM Guidelines for the Diagnosis and Management of Patients with Thoracic Aortic Disease. Circulation. 2010; 121(13). DOI: 10.1161/cir.0b013e3181d4739e

4. Smith W, Ferguson T, Ryan T, Landolfo C, Peterson E. Should coronary artery bypass graft surgery patients with mild or moderate aortic stenosis undergo concomitant aortic valve replacement? J Am Coll Cardiol. 2004; 44(6): 1241-1247. DOI: 10.1016/ j.jacc.2004.06.031

5. Ahmed OF, Al Kaabi LS, Kakamad FH, Mohammed SH, Salih RQ. Early outcome of combined coronary artery bypass grafting and valve surgery. $J$ Cardiothorac Vasc Surg. 2018;5(1):1e5.

6. Yasuda H, Nakatani S, Stugaard M et al. Failure to prevent progressive dilation of ascending aorta by aortic valve replacement in patients with bicuspid aortic valve: comparison with tricuspid aortic valve. Circulation. 2003; 108 Suppl 1: II291-II294. DOI: 10.1161/ 01.cir.0000087449. 03964.fb

7. Svensson L, Kim K, Blackstone E et al. Bicuspid aortic valve surgery with proactive ascending aorta repair. $J$ Thorac Cardiovasc Surg. 2011;142(3):622-629.e3. DOI: 10.1016/j.jtcvs.2010.10.050

8. Tsutsumi K, Hashizume K, Inoue Y. Natural history of the ascending aorta after aortic valve replacement: risk factor analysis for late aortic complications after aortic valve replacement. Gen Thorac Cardiovasc Surg. 2015;64(5):243-250. DOI:10.1007/s11748-015-0617-9

9. Vicchio M, Feo M, Giordano S, Provenzano R, Cotrufo M, Nappi G. Coronary artery bypass grafting associated to aortic valve replacement in the elderly: survival and quality of life. J Cardiothorac Surg. 2012;7(1). DOI:10.1186/1749-8090-7-13

10. Gertz ZM, Levitt SA, Epps KC, Bavaria JE, Moser GW, Kolansky DM. Cardiac catheterization in patients with ascending aortic aneurysms: safety, success, and prevalence of coronary artery disease. $J$ Invasive Cardiol. 2014;26(6):241-244.

11. Jackson V, Eriksson M, Caidahl K, Eriksson P, FrancoCereceda A. Ascending aortic dilatation is rarely associated with coronary artery disease regardless of aortic valve morphology. J Thorac Cardiovasc Surg. 2014;148(6):2973-2980.e1. DOI: 10.1016/ j.jtcvs.2014.08.023

12. Hansson G. Inflammation, Atherosclerosis, and coronary artery disease. $N$ Engl $J$ Med. 2005;352(16):1685-1695. DOI:10.1056/nejmra043430

13. Kieffer E, Chiche L, Baron J, Godet G, Koskas F, Bahnini A. Coronary and Carotid Artery Disease in Patients with Degenerative Aneurysm of the Descending Thoracic or Thoracoabdominal Aorta: Prevalence and Impact on Operative Mortality. Ann Vasc Surg. 2002; 16(6): 679-684. DOI:10.1007/s10016001-0315-1

14. Marin M, Hollier L, Ellozy S et al. Endovascular Stent Graft Repair of Abdominal and Thoracic Aortic Aneurysms. Ann Surg. 2003; 238(4): 586-595. DOI: 10.1097/01.sla.0000090473. 63393.e9

15. Narayan P, Rogers C, Caputo M, Angelini G, Bryan A. Influence of concomitant coronary artery bypass graft 
on outcome of surgery of the ascending aorta/arch. Heart. 2005; 93(2): 232-237. DOI:10.1136/ hrt.2006.090860

16. Ueda T, Shimizu H, Shin $\mathrm{H}$ et al. Detection and management of concomitant coronary artery disease in patients undergoing thoracic aortic surgery. Jpn $J$ Thorac Cardiovasc Surg. 2001; 49(7): 424-430. DOI:10.1007/bf02913907

17. Keogh BE, Kinsman R. UKCSR: miscellaneous operations for acquired heart disease financial year 2003. In: Keogh BE, eds. Fifth National Adult Cardiac Surgical Database Report 2003. Oxfordshire: Dendrite Clinical Systems, 2004: 46.

18. Miller JS, Lemaire SA, Coselli JS. Evaluating aortic dissection: when is coronary angiography indicated? Heart. 2000;83(6):615-616. DOI:10.1136/heart.83.6.615

19. Penn M, Smedira N, Lytle B, Brener S. Does coronary angiography before emergency aortic surgery affect in-hospital mortality? J Am Coll Cardiol. 2000;35(4): 889-894. DOI:10.1016/s0735-1097(99)00638-5.

20. Vahanian A, Alfieri O, Andreotti F et al. Guidelines on the management of valvular heart disease (version 2012): The Joint Task Force on the Management of Valvular Heart Disease of the European Society of Cardiology (ESC) and the European Association for Cardio-Thoracic Surgery (EACTS). Eur Heart J. 2012; 33: 2451-2496. DOI.org/10.1093/eurheartj/ehs109

21. Prenger K, Pieters F, Cheriex E. Aortic Dissection After Aortic Valve Replacement: Incidence and Consequences for Strategy. J Card Surg. 1994; 9(5): 495-499. DOI:10.1111/j.1540-8191. 1994.tb00882.x

22. Crawford E, Svensson L, Coselli J, Safi H, Hess K. Aortic Dissection and Dissecting Aortic Aneurysms. Ann Surg. 1988; 208(3): 254-273. DOI:10.1097/00000658198809000-00002

23. Davies R, Goldstein L, Coady M et al. Yearly rupture or dissection rates for thoracic aortic aneurysms: simple prediction based on size. Ann Thorac Surg. 2002; 73(1): 17-28. DOI:10.1016/s0003-4975(01)03236-2

24. Carrel T, Vonsegesser L, Jenni R et al. Dealing with dilated ascending aorta during aortic valve replacement: advantages of conservative surgical approach Eur $J$ Cardiothorac Surg. 1991; 5(3): 137-143. DOI:10.1016/ 1010-7940(91)90212-3

25. Gambardella I, Gaudino M, Lau C et al. Contemporary results of hemiarch replacement. Eur $J$ Cardiothorac Surg. 2017; 52(2): 333-338. DOI:10.1093/ejcts/ezx071.

26. Lim J, Jung S, Kim J et al. Concomitant Replacement of the Dilated Ascending Aorta During Aortic Valve Replacement; Does It Increase the Perioperative Morbidity and Mortality Risks? J Card Surg. 2013; 28(3): 285-290. DOI:10.1111/jocs.12111.

27. Wallen T, Habertheuer A, Bavaria J et al. Elective Aortic Root Replacement in North America: Analysis of STS Adult Cardiac Surgery Database. Ann Thorac Surg. 2019; 107(5): 1307-1312. DOI: 10.1016/j.athoracsur. 2018.12.039. 